\title{
DESVENDANDO O AGRONEGÓCIO: FINANCIAMENTO AGRÍCOLA E O PAPEL ESTRATÉGICO DO SISTEMA DE ARMAZENAMENTO DE GRÃOS
}

\author{
Samuel Frederico*
}

\section{RESUMO:}

Durante a segunda metade do século XX e início do século XXI, ocorreu a transição de uma política de financiamento agrícola, realizada exclusivamente pelo Estado, para uma regulação feita primordialmente pelo mercado. A partir da década de 1990, o Estado brasileiro criou mecanismos de política agrícola que transferiram, sobretudo para as grandes empresas, o poder de financiamento da produção. Uma década depois, foram criados novos instrumentos, que permitiram também a entrada de investidores e fundos de pensão. Entretanto, para que as políticas de abastecimento - feitas pelo Estado - e de financiamento - realizadas pelas empresas e especuladores - se concretizem é necessário o controle de um sistema de armazenamento que permita a fluidez territorial dos grãos. Este artigo se propõe a analisar as mudanças ocorridas nas políticas de financiamento do agronegócio brasileiro e a importância do sistema de armazenamento para que as políticas tanto do Estado quanto das empresas se efetivem.

\section{PALAVRAS-CHAVE:}

financiamento agrícola; políticas de abastecimento; sistema de armazenamento; política das empresas; especulação financeira.

\begin{abstract}
:
Understanding agribusiness: agricultural financing and the strategic role of grain storage system During the second half of the 20th century and the beginning of the 21 st century, there was a change from an agricultural financing policy, performed exclusively by the government, to a regulation conducted especially by the market. From 90's Brazilian government created mechanisms for agricultural policies that transferred, especially to big companies, the power of financing production. A decade later, new instruments were created, enabling the participation of investors and pension funds. However, to make supply policies conducted by the government, and the financing policies performed by companies and speculators work, there must be a control of the storage system, enabling efficient grain transportation. This article aims at assessing the changes on financing policies of the Brazilian agribusiness and the importance of storage system so that both the government and companies' policies can be effective.
\end{abstract}

\section{KEY WORDS:}

agricultural financing; supply policies; storage system; companies' policies; financial speculation.

\section{Introdução}

A cada fase do capitalismo mundial (CARROUÉ, 2002), o território brasileiro, em particular o seu uso agrícola, é organizado de forma proeminente por vetores externos. No período do capitalismo mercantil, a partir do

Renascimento e das "Grandes Navegações", a inserção periférica do Brasil como extensão da economia-mundo europeia, transformou seu território num grande produtor e exportador de monoculturas. Após alguns séculos de exploração 
exaustiva de seu solo, o território brasileiro, agora como um Estado independente, se subordinou à lógica industrial imposta pelo capitalismo mundial, mantendo seu caráter dependente dentro da divisão internacional do trabalho. Nesta fase, que perdurou, segundo Carroué (2002), entre o início do século XIX e a metade do século XX, o Brasil continuou exportador de produtos primários in natura, como o caso do café, processado na Europa e nos EUA.

Após a Segunda Guerra, transformações significativas alteraram o padrão de organização da agricultura brasileira, sem, no entanto, alterar a sua dependência em relação aos vetores externos da economia. Esse período denominado por Carroué (2002) de Capitalismo Financeiro, se caracteriza por uma agricultura cada vez mais consumidora de capital e exigente de grandes investimentos, o que tornou o nexo financeiro primordial em todas as relações.

Este último período que também é chamado por Santos $(1985 ; 1994)$ de técnicocientífico e informacional, caracteriza-se, também, pela incorporação, na agricultura brasileira, de sistemas técnicos com grande conteúdo em ciência e informação. Nas palavras de Latour (1991), foram incorporados objetos híbridos, que possuem uma "constituição mista", devido à inseparabilidade entre as normas (jurídicas, técnicas, políticas e econômicas), inerentes à sua criação e uso, e sua materialidade. A presença de objetos cada vez mais performáticos e concretos (SIMONDON,1958), impingiu na agricultura brasileira uma relação de dependência, sobretudo com relação às grandes firmas mundiais.

O agronegócio, historicamente ligado ao Estado e produtores, passa a ser primordialmente o negócio das empresas. Para tanto, no Pósguerra estas, com a cooperação imprescindível do Estado, promoveram uma grande transformação na agricultura brasileira por meio da implantação da chamada Revolução Verde. A adoção de novos sistemas técnico-agrícolas, como sementes melhoradas e o uso intensivo de agrotóxicos, promoveram um aumento da produção e da produtividade dos grãos e possibilitaram também a expansão da agricultura na direção dos cerrados.

O Estado foi o principal responsável pela incorporação ao território de uma nova tecnoesfera (rodovias, portos, usinas hidrelétricas, armazéns, maquinário agrícola) indissociável da difusão de uma psicoesfera, pautada na ideologia do consumo, do crescimento econômico e do desenvolvimentismo (SANTOS, 1996). A constituição de uma base material e ideológica foi de fundamental importância para a modernização da agricultura brasileira. A adoção de uma política de substituição de importações estimulou o aumento e diversificação da produção agrícola e internalizou as principais empresas multinacionais de sementes, maquinário e agrotóxicos entre as décadas de 1960 e 1970.

Naquele momento, o Estado foi o grande financiador da modernização agrícola, por meio da concessão de créditos fartos e subsidiados aos produtores, sobretudo aqueles localizados nas regiões de expansão dos fronts agrícolas (SANTOS \& SILVEIRA, 2001). Entretanto, o emergir da década de 1980, trouxe uma nova realidade financeira para o Estado brasileiro que começa a delegar às empresas a responsabilidade pelo financiamento da produção. Implantou-se no território uma nova psicoesfera, que acentuou o consumo e diminuiu a intervenção estatal. A chamada política neoliberal delegou ao mercado a regulação da oferta e demanda de grãos, extinguindo os estoques e armazéns públicos.

A transição do financiamento estatal para o financiamento privado da agricultura ficou evidente nas políticas agrícolas adotadas a partir da segunda metade da década de 1990. O governo federal praticamente extinguiu seus mecanismos tradicionais de política, tais como as aquisições diretas e empréstimos, e transferiu para a iniciativa privada a responsabilidade pelo custeio e comercialização. A partir da década de 2000, a crescente financeirização da agricultura começou a atrair também novos agentes, que teoricamente não possuem nenhuma relação direta com a produção, como os investidores e "especuladores" financeiros. No momento coevo, estimulados pelo aumento dos preços 
internacionais dos grãos, grandes investidores, buscam lucros a curto e médio prazo. Vive-se um círculo vicioso, entre o aumento dos preços dos grãos e a especulação financeira mundial.

Contudo, para que a política, tanto do Estado quanto das empresas, se efetive realmente são necessários a existência e o controle de uma base material que viabilize a produção e a fluidez dos grãos. Os diversos tipos de financiamento agrícola, desde o crédito disponibilizado pelo Estado, até a compra de títulos futuros realizada pelas empresas financeiras, requerem, para o sucesso de suas políticas, a possibilidade da fluidez territorial dos produtos agrícolas. Esta relação de dependência torna o sistema de armazenamento um elo estratégico entre a compra e a venda dos produtos, pois permite a distribuição dos grãos no tempo, por meio da formação de estoques, e no território. O controle deste sistema técnico é imprescindível tanto para a realização das políticas públicas, quanto para os negócios das empresas processadoras e exportadoras de grãos, tornando-se essencial também para os especuladores financeiros.

Dentro desta lógica, o objetivo deste artigo é demonstrar como ocorreu a transição de uma política agrícola feita eminentemente pelo Estado, mediante o fornecimento de crédito subsidiado, para uma regulação política das empresas, destacando a importância estratégica do sistema de armazenamento para a efetivação dessas políticas.

\section{A transição da política agrícola estatal para a regulação política das empresas}

A transição da década de 1980 para a de 1990 foi um momento de grandes mudanças na agricultura brasileira. A maior delas foi o arrefecimento das políticas agrícolas estatais e a participação cada vez mais crescente da ingerência das grandes empresas na regulação dos circuitos espaciais produtivos agrícolas (CASTILLO \& FREDERICO, 2004).

Como bem demonstrado por Delgado (1985), o Estado foi o principal financiador do processo de modernização e expansão territorial da agricultura brasileira entre o pós-guerra e meados da década de 1980. A partir de então, os problemas advindos da crise fiscal, da estagnação do crescimento econômico e a disseminação da ideologia liberal induziram a uma menor participação estatal na realização direta das políticas agrícolas, restando ao Estado, apenas a função de mediador das transações comerciais entre os agentes privados.

Pautados em autores como Delgado (1985), Coelho (2001) e Graziano da Silva (1996), propomos uma divisão da evolução da política agrícola brasileira em três fases. A primeira, a qual denominamos "Gênese da política agrícola e produção incipiente de grãos", vai de 1930 até 1965 e caracteriza-se por forte intervenção estatal, predominando a produção e exportação basicamente de café e açúcar. A segunda fase denominada "Fase da modernização da agricultura e expansão dos fronts agrícolas", perdurou de 1965 a 1985 e caracteriza-se também por forte intervenção estatal com o objetivo de modernizar, diversificar e expandir a agricultura brasileira, inspirada na política de substituição de importações. A terceira é denominada fase da "Transição da política agrícola estatal para a regulação privada" e inicia-se em meados da década de 1980, caracterizando-se pela menor intervenção direta do Estado, com o fim do fornecimento do crédito subsidiado, e pela crescente participação das empresas (tradings, agroindústrias, indústrias de insumos e maquinário agrícola) e de agentes financeiros no fornecimento do crédito e regulação da política agrícola.

A primeira fase foi o período da criação de diversos órgãos públicos como o Conselho Nacional do Café - CNC (1931), o Instituto do Açúcar e Álcool - IAA (1933) e principalmente a Comissão de Financiamento da Produção - CFP (1943). Apesar da forte intervenção estatal, inspiradas nas políticas intervencionistas do New Deal norte-americano, as políticas agrícolas brasileiras não conseguiram estimular o aumento da produção de grãos, ficando a agricultura do país restrita ao café e ao açúcar. Este fato se 
explica, segundo Coelho (2001, p. 12), pelas dificuldades operacionais, provocadas principalmente pela falta de um sistema de armazenagem, que garantisse a formação de estoques regulatórios imprescindíveis ao combate das oscilações de preços e oferta de grãos.

Para o autor, a negligência estatal com a política agrícola e a rápida urbanização daquele período culminaram na crise de abastecimento de 1962. Para solucionar o problema, o Plano Trienal de Desenvolvimento (1963-1965) previa a realização da Reforma Agrária, atribuindo, com razão, à concentração da estrutura fundiária a responsabilidade pela ineficiência produtiva. Como a realização de tal política se tratava de um processo demorado, o governo federal propôs medidas de curto prazo como: a garantia de preços mínimos ao produtor, o controle dos preços para o consumidor, a criação de uma rede oficial de estabelecimentos varejistas e a construção de uma rede de armazéns. Para regular as políticas implementadas e o sistema de armazenamento foram criadas a Companhia Brasileira de Alimentos (Cobal), a Superintendência Nacional de Abastecimento (SUNAB) e a Companhia Brasileira de Armazenamento (Cibrazem).

O evento que determinou a transição da primeira para a segunda fase foi a criação do Sistema Nacional de Crédito Rural (SNCR) e a reformulação da Política Geral de Preços Mínimos (PGPM) em 1965. Esta fase caracteriza-se pelo uso intenso do crédito rural e da PGPM, por parte do Estado, para modernizar a agricultura e expandir os fronts agrícolas. Os créditos estatais de investimento, custeio e comercialização eram a "espinha dorsal" da política agrícola, assegurando aos produtores a aquisição dos novos sistemas técnicos (irrigação, mecanização, fertilizantes químicos, sementes melhoradas) e o escoamento dos produtos.

A criação do SNCR foi de fundamental importância para a expansão dos fronts ao aumentar a disponibilidade de crédito subsidiado para o Centro-Oeste, como demonstra a tabela a seguir.

\section{Tabela 01 - Participação regional no crédito rural em anos selecionados (Percentagem)}

\begin{tabular}{|r|r|r|r|r|r|}
\hline Ano & Sudeste & \multicolumn{1}{l|}{ Sul } & \multicolumn{1}{l|l}{$\begin{array}{l}\text { lentro- } \\
\text { Oeste }\end{array}$} & $\begin{array}{l}\text { Norte/ } \\
\text { Nordeste }\end{array}$ & Brasil \\
\hline 1965 & 47 & 30 & 0 & 23 & 100 \\
\hline 1970 & 45,6 & 31,8 & 6,5 & 16,1 & 100 \\
\hline 1975 & 35,7 & 38,2 & 10,1 & 15 & 100 \\
\hline 1980 & 34,1 & 35,8 & 10,5 & 19,6 & 100 \\
\hline 1985 & 26,2 & 41,6 & 16,3 & 15,9 & 100 \\
\hline
\end{tabular}

Fonte: Banco Central do Brasil - Adaptação Coelho (2001)

Antes da criação do SNCR, a região Centro-Oeste não tinha nenhuma participação no crédito rural. No ano de 1970, cinco anos após a sua criação, a região participou com $6,5 \%$ e em 1985 , com $16,3 \%$ do total do crédito disponível. As demais regiões tiveram um decréscimo percentual, entre 1965 e 1985, como o Sudeste que passou de $47 \%$ para $26,2 \%$ e as regiões Norte e Nordeste que, juntas, decaíram de $23 \%$ para $15,9 \%$, no mesmo período. A exceção foi a região Sul, tradicional belt agrícola, que teve um aumento percentual de $30 \%$ para $41,6 \%$ das alocações do crédito rural, devido à expansão da produção de soja e milho.

Outro mecanismo indutor do aumento da produção agrícola foi a PGPM, por meio de seus dois principais instrumentos de política utilizados nesta fase: o Empréstimo do Governo Federal (EGF) e a Aquisição do Governo Federal (AGF). O EGF tinha como objetivo reduzir a sazonalidade da oferta e dos preços dos produtos agrícolas por meio de financiamento aos produtores, para que esses pudessem armazenar os grãos para venda futura ${ }^{1}$. Apesar de originalmente criado para financiar exclusivamente produtores e cooperativas, mudanças no projeto inicial permitiram que os recursos financeiros fossem contraídos também por empresas beneficiadoras e processadoras de produtos agrícolas. Estas últimas, devido ao seu maior poder financeiro e lobby político, foram as maiores beneficiadas contraindo, entre 1965 e 1985, 36\% do total dos empréstimos, contra $34 \%$ dos produtores e $30 \%$ das cooperativas. A soja foi o principal produto 
beneficiado pelo EGF, por se tratar de uma produção em larga escala e em grande parte destinada ao processamento. As regiões Sul e Sudeste, que naquele período concentravam as maiores plantas agroindustriais, também absorveram a maior parte dos recursos, cerca de $70 \%$ (Conab).

A política de Aquisição do Governo Federal (AGF), que ainda existe de forma incipiente, consiste na compra direta pelo governo federal, no preço mínimo, com o objetivo de formar estoques reguladores de oferta e demanda de grãos. A responsabilidade e os custos do transporte e armazenagem dos grãos ficavam sob responsabilidade do Estado, dependendo este da capacidade estática de armazenamento disponível para a estocagem dos grãos. Esta política ao mesmo tempo em que estimulou a expansão dos fronts agrícolas, sobretudo durante a década de 1970, através da compra e escoamento dos excedentes de milho e arroz produzidos no Centro-Oeste, também foi de fundamental importância para o abastecimento de regiões onde a demanda por estes grãos é menor do que a produção como o Norte e Nordeste. Entre 1970 e 1985 , cerca de $50 \%$ das aquisições feitas pelo governo federal foram realizadas na região Centro-Oeste, devido à carência do sistema de transportes e com o objetivo explícito de estimular a expansão da agricultura nessa região.

O EGF e a AGF foram os principais mecanismos de política de preços mínimos até o final da década de 1980. Na década seguinte, estes foram substituídos por novos instrumentos como a Opção de Venda e o Prêmio para Escoamento do Produto, que tiveram como objetivo diminuir a intervenção do Estado, tornando-o apenas mediador das relações comerciais. Durante a vigência dessas políticas, a maioria absoluta dos financiamentos foi contraída na forma de EGF, cerca de $90 \%$, cabendo o restante para as aquisições diretas do governo federal.

O crédito subsidiado e a PGPM alcançaram seus objetivos ao promover a ocupação definitiva dos cerrados e propiciar a substituição das importações agrícolas. A modernização e diversificação da agricultura brasileira fizeram com que o país deixasse de ser um grande importador para se tornar exportador de produtos agropecuários, como demonstra a tabela a seguir.

Tabela 02 - Exportações brasileiras de produtos agropecuários - US\$ bilhões

\begin{tabular}{|l|r|r|r|r|r|}
\hline & 1965 & 1970 & 1975 & 1980 & 1985 \\
\hline Soja e derivados & 0 & 0,18 & 2,9 & 3,32 & 3,2 \\
\hline Café & 2 & 2,63 & 2,16 & 4,07 & 3,28 \\
\hline Acúcar & 2 & 0,34 & 2,47 & 1,88 & 0,45 \\
\hline Laranja & 0 & 0 & 0,18 & 0,49 & 0,94 \\
\hline Agrícolas (total) & 4,04 & 5,76 & 10,84 & 15,22 & 13,08 \\
\hline
\end{tabular}

Fonte: Banco Central do Brasil. Adaptação Coelho (2001).

Como pode ser observado na tabela 02 , no ano de 1965, quando foi criado o SNCR, as exportações brasileiras de produtos agropecuários restringiam-se basicamente à venda de café e açúcar, que perfaziam $99 \%$ das exportações agrícolas. A partir desta data a pauta exportadora começa a se diversificar com o aumento, sobretudo das exportações de soja e derivados, que chega a se equivaler em valor às exportações de café em 1985, ultrapassando-a posteriormente. No final do período, os dois principais produtos (soja e café) representavam $49,5 \%$ das exportações agrícolas, no valor aproximado de US\$ 6,5 bilhões, com a laranja e - açúcar em terceiro e quarto lugares respectivamente.

Contudo, como demonstra Graziano da Silva (1988), se por um lado o crédito rural subsidiado e a PGPM promoveram o aumento e a diversificação da produção agrícola, por outro acentuou as desigualdades históricas do campo brasileiro. Estas medidas criaram o que o autor denomina de "modernização conservadora" da agricultura brasileira, ao privilegiar um modelo de financiamento que beneficiava exclusivamente grandes produtores e empresas ligados a uma prática agrícola pautada na grande propriedade e na monocultura. Estas medidas excluíam todos os outros tipos de agricultura possíveis, sobretudo aquelas praticadas pelos pequenos produtores. 
A terceira e última fase, denominada de "Transição da política agrícola estatal para a regulação privada", se inicia a partir da segunda metade da década de 1980, e caracteriza-se pela menor intervenção estatal nas políticas agrícolas, principalmente no que concerne ao financiamento e à formação de estoques públicos. Segundo Mazzali (2001, p. 33), a desarticulação e imobilização da intervenção do Estado se devem a dois fatores centrais: os problemas fiscais associados ao comprometimento da maior parte da receita da União com o pagamento da dívida pública e a adoção da política neoliberal com ênfase no "Estado mínimo". A nova diretriz do Estado, baseada no controle fiscal e da inflação, somada a uma postura menos intervencionista, redundaram na diminuição do crédito agrícola como um todo, como pode ser visualizado no gráfico a seguir.

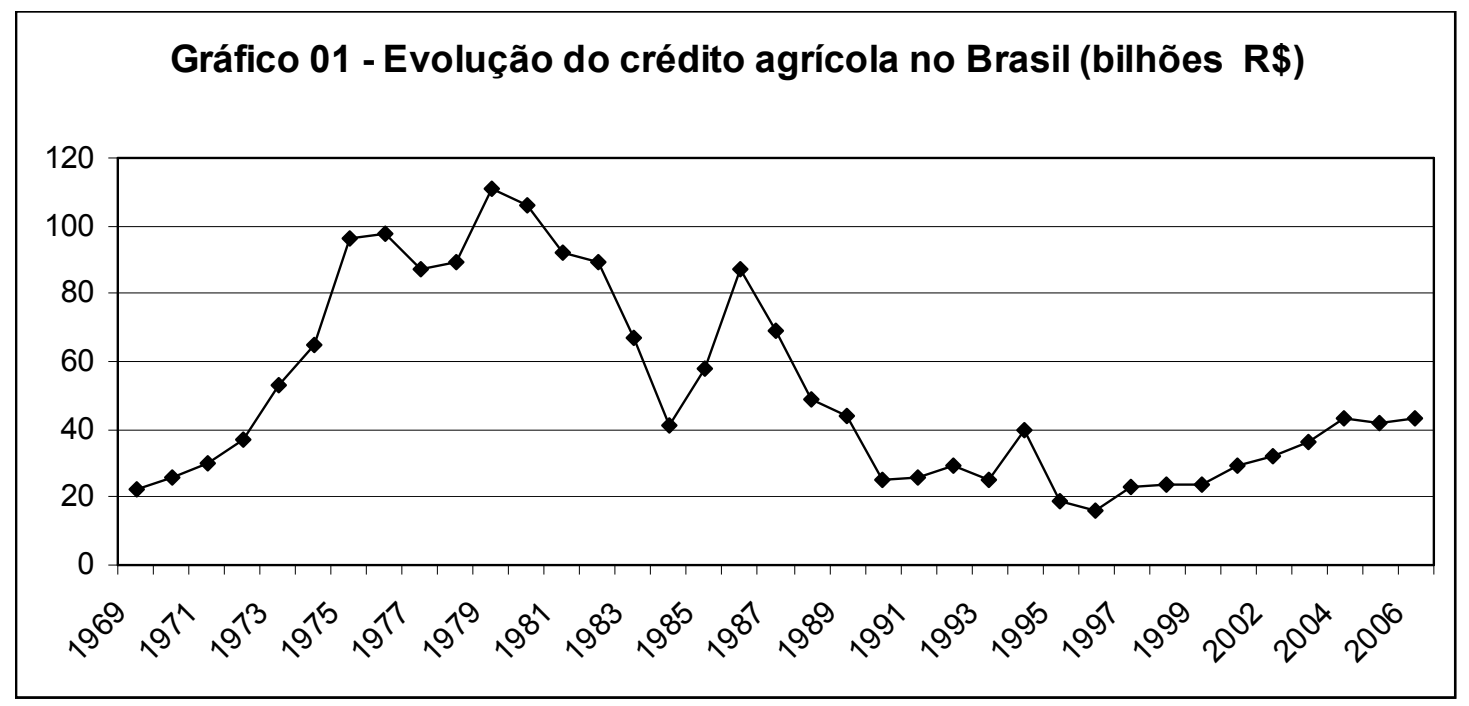

Fonte: Anuário Estatístico do Crédito Rural, 2006.

O gráfico 01 permite visualizar o grande volume de recursos disponibilizados pelo Estado durante a fase de "Modernização da agricultura e expansão dos fronts agrícolas", entre o final da década de 1960 e 1985, seguida pela diminuição gradativa até 1997, quando o crédito agrícola passa a ter um pequeno, mas constante aumento anual $^{2}$.

Até 1985, a maior parte dos recursos agrícolas era disponibilizada pelo Tesouro Nacional, responsável, naquele ano, por $92 \%$ do crédito agrícola. Com a eliminação do subsídio, a participação do Tesouro Nacional começa a diminuir rapidamente, chegando a $10,9 \%$ em 1990, a 7,8\% em 1995 e a 2,6\% em 2000 (Banco Central do Brasil). Em 1986, foi criada a poupança rural para ser a grande substituta do Tesouro, sendo esta formada por fundos constitucionais que substituíram e complementaram as fontes tradicionais de crédito. O predomínio da poupança rural vai até 1996, quando a maior parte do financiamento agrícola passou a ser proveniente de recursos obrigatórios dos bancos públicos e privados (exigibilidades), assim como de outros mecanismos, como a Cédula do Produtor Rural (CPR).

Esta última foi criada pelo Banco do Brasil em 1994, com o intuito de facilitar a participação das empresas de insumos, agroindústrias e tradings no fornecimento de crédito aos produtores agrícolas. A CPR tem como objetivo custear a produção e assegurar preços futuros, 
consistindo na venda antecipada pelo produtor (antes do plantio) de parte de sua produção aos agentes privados. Desta forma, o governo transferiu para a iniciativa privada o financiamento do custeio da produção, restando ao Estado a prioridade de fornecer o crédito para comercialização e investimento.

Segundo Bernardes (2005) apud Brandão Filho (2007), a CPR estabeleceu um vínculo de dependência dos produtores agrícolas com relação às tradings. De acordo com a autora, cerca de $70 \%$ dos financiamentos a sojicultores no Mato Grosso são realizados por apenas 5 empresas: ADM, Bunge, Cargill, Louis Dreyfus e Amaggi. O restante dos recursos é proveniente dos bancos públicos e privados. Segundo dados do Banco do Brasil, foram destinados pelo banco $R \$ 4,4$ bilhões, no ano de 2004, para o financiamento agrícola via CPR, contra R\$15 bilhões das tradings, agroindústrias e fornecedores de insumos.

Associado às alterações promovidas no crédito agrícola, o governo federal adotou também outras medidas para reduzir sua intervenção na agricultura. Foram extintos, no início da década de 1990, diversos institutos - Emater, Instituto do Açúcar e Álcool (IAA) e o Instituto Brasileiro do Café (IBC) -, e reformuladas a PGPM e a política de formação de estoques públicos.

A adoção de uma política de orientação liberal propalou a concepção de que não era mais necessária a constituição de estoques regulatórios. As oscilações de demanda e preços dos produtos agrícolas seriam compensadas pelas importações, ou seja, caberia ao livre mercado regular os preços e a oferta dos produtos. Para adequar a PGPM a esse novo contexto foi criado o Prêmio de Liquidação de Estoque. Por meio desta medida o governo federal praticamente eliminou os estoques públicos. Os estoques de milho, que representavam mais de 5 milhões de toneladas em 1995, passaram para 762 mil toneladas em 1998. Com a diminuição dos estoques, o governo federal começa a se desfazer também dos armazéns estatais por meio de leilões. No final da década de 1980, a Conab (Companhia Nacional de Abastecimento) controlava cerca de 800 armazéns, número que foi reduzido para 76 em 2001, chegando os estoques públicos de grãos a praticamente zerar no mesmo ano (Conab).

Além da política de liquidação dos estoques, a partir de 1996, as tradicionais políticas de aquisição (AGF) e empréstimos (EGF) do governo federal passaram a ser substituídas pelas recém criadas políticas de Opção de Venda e Prêmio para o Escoamento do Produto. Com a adoção destas políticas, o Estado não precisaria mais adquirir os grãos, ele apenas pagaria um Prêmio à iniciativa privada, para que esta comprasse e transportasse os produtos agrícolas. Com esses novos mecanismos, o Estado passou a desempenhar a função de mediador das operações realizadas entre operadores privados. A AGF se manteve apenas para a remoção de estoques de regiões de difícil acesso e o EGF continuou a ser concedido apenas na modalidade "Sem Opção de Compra".

O Prêmio de Escoamento do Produto (PEP) foi implementado com o objetivo de transferir a produção dos produtores da região de origem para as regiões de consumo, sem a necessidade da aquisição direta do governo federal e garantindo ao produtor o preço mínimo. Para estimular o comércio, o governo federal, por meio da Conab, paga aos compradores dos grãos um prêmio, cujo valor foi previamente arrematado em leilão, e que reflete a diferença entre o preço de mercado e o preço mínimo. O governo federal lança o leilão do PEP quando o preço de custo do produto posto na região de destino (onde ocorre o beneficiamento, industrialização ou consumo), não viabiliza o recebimento do preço mínimo pelos produtores na região de produção. Em suma, o PEP é um estímulo do Estado, ofertado à iniciativa privada, para garantir o preço mínimo ao produtor e, sobretudo o transporte do produto até as regiões com maiores problemas de abastecimento como o Norte, Nordeste e norte de Minas Gerais.

Para a remoção dos estoques públicos, formados por meio de AGF ou Opção de Venda, o governo federal criou um outro mecanismo, semelhante ao PEP, denominado Valor de Escoamento do Produto (VEP). Este mecanismo tem como objetivo estimular o escoamento dos 
produtos estocados nos armazéns públicos ou conveniados à Conab, mediante o pagamento de um prêmio à iniciativa privada. O governo federal estipula, em leilão, o valor máximo do prêmio a ser pago pelo frete e a região de destino dos grãos, e o transportador que oferecer o maior deságio, passa a ter a obrigação de transportar os grãos até a região previamente estipulada.

Outro mecanismo criado para substituir a AGF foi a Opção de Venda. Neste mecanismo, implementado em 1997, o produtor ou cooperativa adquire o direito, por meio do pagamento de um prêmio via leilão, de vender seu estoque para o governo federal, no preço mínimo, em data futura. O produtor não é obrigado a vender o produto ao Governo, caso o preço de mercado no momento da venda esteja maior que o preço mínimo. Este instrumento tem a mesma finalidade da AGF, diferindo desta por ter um custo para o beneficiário e a possibilidade da venda ao Estado ser garantida. Como efeito destes novos instrumentos, as compras governamentais, que antes chegavam a atingir perto de 20 milhões de toneladas de grãos, a partir da década de 2000, não têm ultrapassado 1,8 milhão de toneladas (Banco Central do Brasil).

Para diminuir ainda mais a intervenção estatal no processo de comercialização das safras, o governo federal criou em 2004, um novo instrumento chamado Prop - Prêmio de Risco para aquisição de Produto Agrícola Oriundo de Contrato Privado de Opção de Venda. Na verdade este mecanismo consiste na união entre o PEP e a Opção de Venda, com a diferença que a compra dos grãos não é feita mais pelo Estado e sim pela iniciativa privada, geralmente agroindústrias. Este mecanismo é dividido em duas etapas: na primeira o governo federal lança um prêmio em leilão para o escoamento do produto, que é arrematado por alguma agroindústria (a que oferecer o maior deságio). Na segunda etapa, a agroindústria lança um contrato de Opção de Venda Privado, que é arrematado por alguma cooperativa ou produtor interessado em assegurar a venda, em data futura, dos grãos no preço mínimo. No momento da venda, caso seja interessante para o produtor ou cooperativa (preço de mercado menor que o preço mínimo assegurado), os grãos são vendidos às agroindústrias. Após a realização do transporte do produto pelas agroindústrias, o governo federal paga o prêmio arrematado pela empresa no primeiro leilão.

Estes novos mecanismos estimularam e asseguraram a participação das tradings e agroindústrias no financiamento agrícola. Contudo, a partir da década de 2000 , novos agentes, ligados estritamente ao mercado financeiro, passaram a atuar também no mercado de financiamento de commodities. A entrada dos fundos de investimento e pensão, assim como de investidores particulares, torna ainda mais complexa as relações e mecanismos de financiamento existentes. A maioria das tradings comprava os grãos antecipadamente dos produtores e assegurava imediatamente a venda da mercadoria no mercado futuro, por meio da operação denominada hedge. Desta maneira, elas se protegiam contra as oscilações de preço das commodities. Diferentemente das tradings, as novas empresas financeiras e fundos de pensão, não asseguram a venda futura dos grãos a um preço fixo (hedge), os seus objetivos são justamente lucrar com o aumento a curto prazo do preço dos alimentos por meio da especulação financeira, o que torna ainda mais volátil o mercado.

Os grandes investidores financeiros compram títulos indexados a produtos agrícolas nas bolsas de mercadorias e futuros de todo o mundo, esperando a valorização futura das commodities. O capital destinado à compra dos títulos é repassado aos produtores agrícolas, que os utilizam para custeio e comercialização da produção. No Brasil, esse tipo de financiamento agrícola passou a vigorar a partir de 2004, com a criação de diversos títulos pelo governo federal: Certificado de Depósito Agrícola (CDA), Warrant Agropecuário (WA), Certificado de Direitos Creditórios do Agronegócio (CRA) e Letra de Crédito do Agronegócio (LCA). Tais títulos criaram um elo de ligação entre o agronegócio e o mercado financeiro, abrindo a possibilidade de grandes investidores estrangeiros financiarem a produção agrícola brasileira. 
O CDA é um titulo de promessa de entrega de produto agropecuário depositado em armazém, e o WA é um título de crédito que confere valor de penhor sobre o produto descrito no CDA. Esses títulos são emitidos simultaneamente pelo armazenador assim que o produtor deposita as mercadorias nos armazéns. Os títulos são registrados nas bolsas de valores (Bovespa ou BM\&F) e ficam depositados sob custódia, aguardando a sua negociação eletrônica. O comprador do CDA que desejar retirar a mercadoria deve liquidar o WA. Por meio destes mecanismos, os armazenadores adquirem o direito de negociar diretamente o produto, tornando os armazéns grandes casas de negócio ${ }^{3}$.

Dentre os demais mecanismos criados pelo Governo, apenas o LCA (Letra de Crédito do Agronegócio) realizou um número significativo de operações desde 2004. O principal objetivo deste instrumento é aumentar a disponibilidade de capital para os agentes do agronegócio (tradings, agroindústrias, bancos) que financiam e disponibilizam crédito para o produtor rural e cooperativas. Esses agentes podem, por intermédio da LCA, renegociar seus recebíveis originados da negociação com o produtor rural com os investidores financeiros. Todas as operações realizadas têm como lastro as CPRs emitidas por bancos e empresas aos produtores e cooperativas (Conab).

Mecanismos semelhantes, como os criados recentemente no Brasil, já são utilizados em diversas praças financeiras mundiais, permitindo aos novos investidores disputarem os produtos agropecuários com os tradicionais compradores (agroindústrias, tradings e comerciantes). Esta demanda adicional acaba por criar um aumento especulativo dos preços, fato que vem ocorrendo em todo o mundo.

Os novos investidores, para assegurar ainda mais a perspectiva de valorização dos títulos agrícolas, passaram também a adquirir bens de capital como terras agrícolas e sistemas de armazenamento nas principais regiões produtoras do mundo. Essa medida aumenta o poder de especulação destes agentes financeiros, que passam a lucrar também com a valorização das terras e com a guarda dos produtos agrícolas à espera de preços melhores.

\section{O papel estratégico do sistema de armazenamento de grãos na realização das políticas agrícolas.}

A necessidade de armazenagem está presente, com maior ou menor intensidade, em todo o circuito espacial dos produtos alimentares: desde os locais de produção, no transporte in natura dos grãos, nos locais de sua industrialização e posteriormente nos estoques formados pelos atacadistas e varejistas, sem contar os grãos exportados e importados. Para Puzzi (1986, p. 35), uma rede armazenadora de grãos "é o aparelhamento destinado a receber a produção de grãos, conservá-los em perfeitas condições técnicas e redistribuí-los, posteriormente".

A existência de uma rede armazenadora é de fundamental importância não só para o escoamento das safras de grãos, mas também, para a realização de políticas de abastecimento e expansão da produção agrícola. O descompasso entre a sazonalidade da produção de grãos e o seu consumo ininterrupto promove, caso não se tenha uma capacidade estática de armazenamento suficiente para a formação de estoques reguladores, uma flutuação dos preços dos produtos. Além das variações estacionais, verificadas todos os anos, existem também, variações interanuais causadas por intempéries naturais ou pela falta de estímulos ao produtor, promovida pela queda dos preços dos grãos. Para se evitar esse tipo de flutuação faz-se necessária a constituição de estoques de longo prazo, que permitam equalizar a oferta com a demanda, mantendo assim, os preços equilibrados.

Acrescido aos estoques regulatórios, existem também os chamados estoques estratégicos, formados com objetivo geopolítico de garantir o suprimento de grãos durante um período de guerras ou, como ressalta Raffestin (1993, p. 255), serem utilizados como "armas políticas" nas relações entre Estados. No caso brasileiro, inexiste qualquer tipo de estoque, os 
regulatórios foram extintos durante a década de $1990^{4}$, devido à crença nas políticas neoliberais, que prediziam que os preços dos alimentos seriam regulados pelo mercado internacional sem interferência do Estado, e os estoques estratégicos chegaram a ser formados em poucos momentos históricos. Além da questão geopolítica, uma rede estratégica serve também para garantir o abastecimento da população em anos de quebras de safras e para armazenar os excedentes agrícolas não exportados imediatamente, podendo fazê-lo ao longo do ano ou nos anos subsequentes em melhores condições de mercado.

As primeiras iniciativas governamentais brasileiras em relação ao armazenamento foram tomadas durante a década de 1940, devido aos problemas de abastecimento provocados pela guerra. Anteriormente, já existiam em território brasileiro armazéns destinados principalmente ao armazenamento de café, mas foi a partir daquela década que o governo federal, através da concessão de créditos subsidiados à iniciativa privada e da construção da sua própria rede armazenadora, começou a intervir de forma mais ativa na elaboração de uma política de abastecimento. No entanto, essa primeira tentativa não obteve êxito devido aos escassos recursos destinados para o financiamento da iniciativa privada.

Como resposta, na década de 1950, diversos estados formaram as suas próprias companhias de armazenamento como a CASEMG em Minas Gerais, a CEAGESP no estado de São Paulo, a CESA no Rio Grande do Sul, a COPASA no Paraná, a CASEGO em Goiás, a CASEB na Bahia, a CAGEP em Pernambuco, a CASEMAT em Mato Grosso, a CASES no Espírito Santo e a CASEAL em Alagoas. No plano federal foi formada a AGEF - Armazéns Gerais Ferroviários da rede Ferroviária Federal S/A e a CIBRAZEM (Companhia Brasileira de Armazenagem) que passou a atuar nos estados não suficientemente equipados com armazéns. Na mesma década em que foram criadas as unidades estaduais, criaram-se também, as primeiras unidades armazenadoras pertencentes às cooperativas, principalmente, na região Sul, com o objetivo de atender ao expressivo crescimento agrícola.

Entre os anos de 1940 e 1960, foram construídos inúmeros armazéns nos diversos estados supracitados. O extinto Instituto Brasileiro do Café (IBC) foi o órgão responsável pela maior expansão da rede armazenadora, devido ao grande aumento da produção de café com a implantação de variedades altamente produtivas oriundas da "Revolução Verde". Naquele período, o IBC detinha a maior capacidade estática de armazenamento do país, com $90 \%$ das suas unidades localizadas nos estados de São Paulo e Paraná.

Durante esse primeiro momento, inúmeros armazéns convencionais foram construídos, estes apresentavam fundo plano e contavam com máquina de limpeza e secador, mas não possuíam transportadores de carga e descarga, pois eram destinados ao armazenamento de sacarias, especialmente de café e arroz. Após os anos de 1960, com a modernização da agricultura brasileira e sua consequente granelização e expansão para os cerrados, os armazéns tornaram-se obsoletos e mal distribuídos.

Para solucionar os problemas supracitados, na década de 1970, o governo federal tornou-se, segundo Puzzi (1986, p. 49), um verdadeiro empresário. Por meio da realização de políticas agrícolas, o Estado passou a atuar de maneira mais efetiva na modernização e no aparelhamento da agricultura brasileira. Naquele período, foram criadas linhas de financiamento estatais para a modernização e construção de infraestruturas agrícolas como: o Programa de Investimentos Agropecuários (Proinap), o Programa de Financiamento e Equipamentos de Irrigação (Profir), o Programa Nacional de Armazenagem Comunitária (Pronac) e o Programa Nacional de Armazenagem (Pronazem).

Este último, vigente entre 1975 e 1979, foi direcionado para a construção de unidades armazenadoras nos fronts e belts agrícolas. Segundo a Conab (2007), esse programa visava suprir o déficit da capacidade estática desde os 
silos de fazenda até os terminais. No início do Pronazem, existia no território brasileiro uma capacidade estática de armazenagem de 36 milhões de toneladas para uma safra de 40 milhões de toneladas, ou seja, um déficit de $10 \%$. No término do programa, a capacidade estática havia aumentado para 50 milhões de toneladas, sendo $20 \%$ superior à quantidade de grãos produzida naquela safra.

A partir da década de 1990, com a adoção de uma política de menor intervenção estatal, a capacidade estática de armazenamento permaneceu praticamente estável, enquanto a produção agrícola continuou a crescer. O grande descompasso gerado entre a quantidade de grãos produzida e a capacidade estática fez com que, no início da década de 2000, muitos autores e revistas especializadas falassem em "apagão da armazenagem"5. O Estado, principal financiador e armazenador até a década de 1980, começou a se desfazer das suas unidades armazenadoras. Na década de 1990, os maiores investimentos foram realizados pelas tradings, principalmente nos fronts agrícolas, devido ao interesse em ter acesso privilegiado e garantido aos grãos.

A participação estatal, que representava a quase totalidade da capacidade de armazenamento existente na década de 1970, reduziu-se a apenas 5\% em 2006, contra 74\% das entidades privadas e $21 \%$ das cooperativas. Dentre as entidades privadas, as grandes empresas exportadoras e processadoras de grãos são as que detêm a maior capacidade instalada, principalmente nos fronts agrícolas. Na região sul do Maranhão, $80 \%$ da capacidade de armazenamento é controlada pelas empresas, sendo que três delas (Bunge, Cargill e Multigrain) controlam, juntas, $59 \%$ do total. Relação semelhante se repete em outras regiões dos fronts como nas diversas regiões agrícolas do Mato Grosso, na região do Gurguéia no Piauí e Oeste da Bahia, onde as empresas controlam $80 \%, 56 \%$ e $55 \%$ da capacidade de armazenamento, respectivamente.

A empresa Bunge é a que possui a maior capacidade estática de armazenamento no território brasileiro. São cerca de 5 milhões de toneladas distribuídas em mais de 100 cidades, localizadas desde os tradicionais belts até os novos fronts agrícolas, passando pelas principais regiões consumidoras e portos exportadores, como pode ser visualizado no mapa a seguir.

O mapa 01 mostra a presença das unidades armazenadoras da empresa Bunge nas principais regiões produtoras de grãos como: o oeste do Paraná, o noroeste do Rio Grande do Sul, a região de Dourados no Mato Grosso do Sul, o sudoeste de Goiás, em quase todo o estado do Mato Grosso, no oeste da Bahia e sul do Piauí e Maranhão.

Sem o controle do sistema de armazenamento as empresas teriam um problema logístico que inviabilizaria a aquisição dos grãos. As formas de financiamento realizadas pelas empresas por meio da CPR (Cédula do Produtor Rural) somente são viabilizadas, na prática, devido à capacidade destas em estocar os grãos.

O controle do sistema de armazenamento é tão estratégico, que os novos agentes financeiros, que entraram recentemente no comércio mundial de grãos, já estão adquirindo silos nas principais regiões produtoras. Os silos podem oferecer a esses investidores novas maneiras de ganhar dinheiro, porque eles seriam capazes de comprar e vender os grãos de fato, e não apenas os seus derivativos financeiros. Além do ganho com a especulação financeira, a posse do sistema de armazenamento conferiria a esses investidores a possibilidade de manter os estoques para venda futura, auferindo assim maiores lucros do que a venda imediata para atender à demanda corrente. Ou, caso haja preços divergentes em partes diferentes do mundo, estoques podem ser enviados para os mercados mais lucrativos. Os "especuladores" também podem fornecer aos armazenadores o dinheiro necessário para sobreviverem aos mercados de commodities mais voláteis, aguardando melhores preços. Nos EUA, os fundos de investimento já começaram a comprar silos como o Ospraie Special Opportunity Fund, que adquiriu 66 silos da empresa armazenadora ConAgra por U\$S 2,1 bilhões. No Brasil a 
Mapa 01 - Localização da capacidade estática de armazenamento - Bunge (2007)

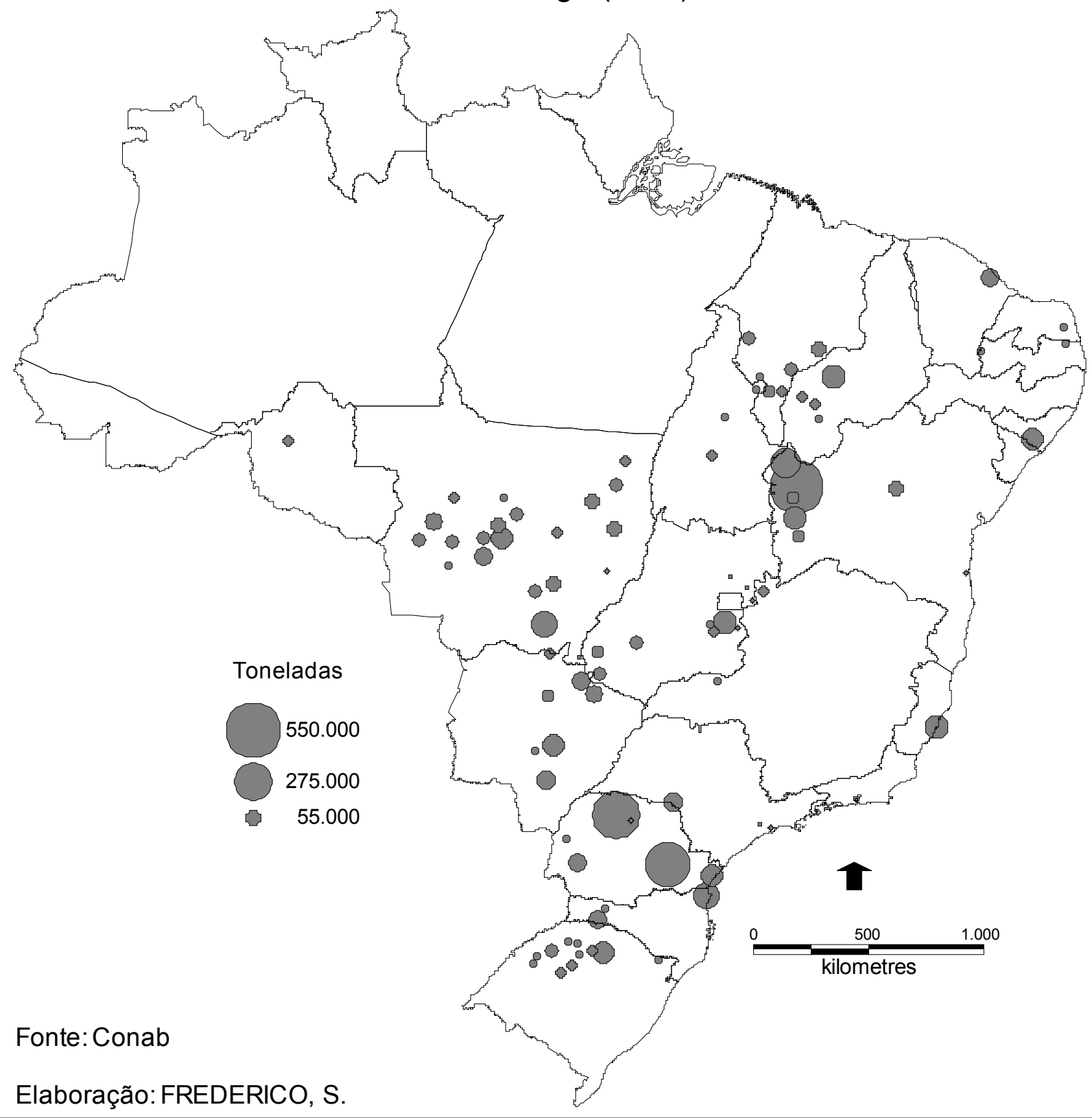


CalixAgro, subdivisão da Louis Dreyfus Commodities, tem recebido aportes de capital de grandes fundos de investimentos, como o AIG Investiment, com o objetivo de adquirir grandes extensões de terras, com o intuito de revendêlas a preços melhores. Muito provavelmente, em breve, os investidores financeiros começarão a adquirir também unidades armazenadoras nas principais regiões produtoras e portos exportadores brasileiros, como vem ocorrendo nos EUA.

\section{Considerações finais}

Em suma, o que essa breve periodização da política agrícola brasileira nos mostra é a transferência de uma regulação feita exclusivamente pelo Estado, financiador de um modelo de modernização agrícola extremamente excludente e conservador, para uma regulação feita primordialmente pelo mercado. Se, no primeiro momento, vigente entre meados da década de 1960 e 1980, a atuação do Estado na agricultura era acusada de "paternalista" e de ser responsável, em grande parte, pela crise de pagamentos e pela inflação da década de 1980 , no segundo momento, como decorrência, adotou-se a ideologia de um "Estado-mínimo" e delegouse à iniciativa privada, sobretudo às grandes empresas, a incumbência da realização da política (SANTOS, 1997). As duas lógicas anteriores, aparentemente contraditórias, na verdade corroboraram e continuam a fomentar a desigualdade imanente do campo brasileiro. Cada fase, dentro do modelo proposto, só fez aumentar a exclusão social e a concentração fundiária, promovendo uma fragmentação do território (SANTOS, 1996) que somente deixou como herança a geração de mais conflitos.

A segunda fase, caracterizada pelo predomínio da política das empresas (SANTOS, 1997), tem se aprofundado e se metamorfoseado com a entrada nos circuitos espaciais produtivos agrícolas dos chamados "especuladores" financeiros. Segundo Charvet (2006, p. 129) esses agentes buscam lucros a curto prazo e jogam com a flutuação dos preços mundiais dos alimentos. Mas, diferentemente do que imaginava o autor, quando alega que esses agentes jamais possuem produtos físicos, os investidores financeiros passaram a adquirir também terras e silos com o intuito de lucrarem duplamente, no mercado físico e financeiro.

Como observado ao longo do artigo, os silos são cada vez mais estratégicos no comércio mundial de grãos e é um dos sistemas técnicos mais cobiçados pelas tradings, e agora pelos especuladores financeiros. O Estado brasileiro que na década de 1990, sob os auspícios de uma política liberal, se desfez das suas unidades armazenadoras tenta agora construir, em lugares estratégicos, silos que permitam a realização de sua política de abastecimento. Num mundo de demanda crescente por grãos e com preços cada vez mais voláteis, fruto da especulação financeira, o controle de uma rede de armazenamento para a formação de estoques estratégicos se tornou vital. Acreditamos ser de fundamental importância a construção de uma rede de armazenamento que permita a fluidez dos grãos entre as principais regiões produtoras e consumidoras, assim como a formação de estoques reguladores que equalizem as variações de demanda e preço dos produtos agropecuários entre as diferentes regiões brasileiras.

Sem a adoção de medidas que aumentem o poder de intervenção política do Estado, a sociedade e o território como um todo tornam-se vulneráveis aos ditames das empresas. Estas, segundo Santos (2000), pautadas pela lógica da competitividade, agem sem nenhuma ética ou altruísmo e o Estado, teoricamente guardião dos interesses da sociedade, tem cooperado com elas por meio de suas normas. Este nexo perverso exclui a maior parte do território e da sociedade e decreta, nas palavras do autor (2000, p. 67), a morte da política. 


\section{Notas}

${ }^{1}$ O EGF possuía duas modalidades, sem ou com opção de venda (SOV/COV), esta última foi largamente a mais utilizada. Os produtores contraíam empréstimos do governo federal, no preço mínimo, com o objetivo de vender os grãos em momento posterior, com melhores preços de mercado. Na data da remissão do empréstimo, o beneficiário tinha duas opções: liquidava o financiamento, arcando com todas as despesas de empréstimo e comercialização, ou entregava os grãos para o Governo, que arcava com os gastos do armazenamento e da comercialização.
2 O rápido aumento verificado nos anos de 1986 e 1987 é decorrente da efêmera estabilização econômica provocada pelo Plano Cruzado.

${ }^{3}$ Segundo Coelho (2001) nos EUA a quase totalidade da comercialização dos grãos é realizada pelos armazéns gerais, chamados de elevators. O lucro destes agentes vem da compra e venda, assim como, do beneficiamento dos grãos.

${ }^{4}$ A partir de 2003, o governo brasileiro adotou novamente uma política de formação de estoques regulatórios, mas ainda em quantidade incipiente.

${ }^{5}$ Ver Weber (2005); Nogueira e Tsunechiro (2005).

\section{Bibliografia}

CARROUÉ, L. Géographie de la mondialisation. Paris: Armand Collin. 2002.

CASTILLO, R. \& FREDERICO, S. 2004. "Circuito espacial produtivo do café e competitividade territorial no Brasil". Bauru, SP: Revista Ciência Geográfica, vol. X, Set./dez., p. 236-241.

CHARVET, Jean-Paul. "L'agriculture dans la mondialisation". In: CARROUÉ, L. (Org.), La mondialisation. Paris: Éditions SEDES/CNED. 2006.

COELHO, Carlos N. "O aproveitamento econômico dos cerrados". Revista de Política Agrícola - Ano X - No01 - jan-fev-mar. Brasília-DF. 2001. pp. 03-05.

CONAB. "Armazenagem agrícola no Brasil". Brasília, DF. 2007.

DELGADO, G.C. Capital financeiro e agricultura no Brasil: 1930-1985. Campinas: Ícone. 1985.

GRAZIANO DA SILVA, J. A nova dinâmica da agricultura brasileira. Campinas - SP: UNICAMP. 1996.

LATOUR, Bruno.. Jamais fomos modernos: ensaio de antropologia simétrica. Rio de Janeiro: Editora 34. 1991.
MAZZALI, L. O processo recente de reorganização agroindustrial: do complexo à organização em rede. São Paulo: Ed. Unesp. 2000.

NOGUEIRA JR., Sebastião \& TSUNECHIRO, Alfredo. "Produção agrícola e infra-estrutura de armazenagem no Brasil". São Paulo: IEA, Informações Econômicas, v.35, N02, fev. 2005. p.07-18.

PUZZI, Domingos. Abastecimento e armazenagem de grãos. Campinas, SP: Instituto Campineiro de Ensino Agrícola. 1986.

RAFFESTIN, Claude. Por uma geografia do poder. São Paulo: Editora Ática, 1993.

SANTOS, Milton. Espaço e método. São Paulo: Ed. Hucitec. (1985) 1997

Técnica, espaço, tempo; globalização e meio técnico-científico informacional. São Paulo: 3a edição, Ed. Hucitec. (1994) 1997.

. A natureza do espaço, técnica e tempo, razão e emoção. 3a edição, São Paulo: Ed. Hucitec. 1996.

"Da política dos Estados à política das empresas" in: Caderno da Escola do Legislativo, Belo Horizonte, MG. 1997. 
SANTOS, Milton. Por uma outra globalização, do pensamento único à consciência universal. Rio de Janeiro e São Paulo: Ed. Record. 2000.

SANTOS, M. \& SILVEIRA, M. L. O Brasil, território e sociedade no início do século XXI. Rio de Janeiro \& São Paulo: Ed. Record. 2001.
SIMONDON, Gilbert. Du mode d'existence des objets techniques. Éditions Montaigne/Aubier. Paris. 1958.

WEBER, Aquino E. Excelência em beneficiamento e armazenagem de grãos. Canoas/RS: Salles Editora. 2005.

Trabalho enviado em junho de 2008

Trabalho aceito em março de 2010 